\title{
O gênero Chamaecrista Moench (Caesalpinioideae) em áreas do entorno do Parque Estadual das Dunas de Natal, Rio Grande do Norte, Brasil
}

\author{
Rubens Teixeira de Queiroz ${ }^{1,3}$ e Maria Iracema Bezerra Loiola ${ }^{2}$
}

Recebido: 11.10.2007; aceito: 30.12.2009

ABSTRACT - (The genus Chamaecrista Moench (Caesalpinioideae) in areas adjoining Parque Estadual das Dunas de Natal, Rio Grande do Norte, Brazil). A study of Chamaecrista Moench was carried out in an urban area in Natal, Rio Grande do Norte. Botanical identification and illustrations were supported by morphological studies and field observations complemented by bibliography and analysis of the herbaria specimens. Ten species were found in the area. The most useful morphological characters for species recognition are habit, inflorescence structure, foliole venation pattern and fruit pedicel size. Four species are new record for the state.

Key words: Diversity, Floristic, Leguminosae, Northeastern Brazil

RESUMO - (O gênero Chamaecrista Moench (Caesalpinioideae) em áreas do entorno do Parque Estadual das Dunas de Natal - RN, Brasil). Foi realizado o levantamento das espécies de Chamaecrista Moench ocorrentes em uma área urbana no município de Natal, Rio Grande do Norte. As identificações, descrições e ilustrações botânicas foram baseadas em coletas e observações de campo, complementadas com o auxílio de bibliografias especializadas e comparação com materiais herborizados. Foram registradas dez espécies para a área. Os caracteres relevantes para a separação das espécies foram hábito, inflorescência, padrão de venação dos folíolos e tamanho do pedicelo frutífero. Quatro táxons constituem novas citações para o Estado.

Palavras-chave: Diversidade, Florística, Leguminosae, Nordeste do Brasil

\section{Introdução}

O Parque Estadual das Dunas de Natal "Jornalista Luiz Maria Alves", criado através do Decreto Estadual $\mathrm{n}^{\circ} 7.237$ de 22/11/1977, constitui a primeira e maior Unidade de Conservação do município de Natal - RN.

De acordo com o único levantamento florístico realizado na área do Parque (Freire 1990), existem cerca de 350 espécies vegetais pertencentes a 78 famílias, das quais 270 são arbóreas. No entanto, não existem registros para espécies do estrato herbáceo.

Chamaecrista Moench inclui cerca de 330 espécies pantropicais, sendo um dos maiores gêneros de Caesalpinioideae. Nas Américas está representado por 266 espécies, tendo com principal centro de diversidade e endemismo o Brasil. Em território brasileiro, o estado de Minas Gerais é um dos principais centros de diversidade desse gênero, com 72 espécies exclusivas (Lewis 2005).
Embora as espécies de Chamaecrista não sejam muito utilizadas economicamente, algumas são citadas como plantas ornamentais (Brito et al. 2006), forrageiras ou daninhas (Lorenzi 2000) e outras como fixadoras de nitrogênio no solo, sendo indicadas para recuperação de solos pobres ou degradados (Faria et al. 1989).

Com base em materiais do herbário local (Herbário UFRN), no Rio Grande do Norte o gênero está relativamente bem representado, com registro desde o litoral até o interior, no entanto, estudos sobre Chamaecrista são inexistentes e suas espécies muito raramente são citadas nos estudos já realizados tanto em território potiguar (Almeida Jr. et al 2006), como em outros estados nordestinos (Araújo et al. 1998, Rocha et al. 2004, Porto et al. 2008).

Dada a observação de considerável diversidade de espécies de Chamaecrista e da inexistência

1. Universidade Federal do Rio Grande do Norte, CB, Departamento de Botânica, Ecologia e Zoologia - DBEZ, 59.072-970 Natal, RN, Brasil. Endereço atual: Universidade Estadual de Campinas, Instituto de Biologia, Departamento de Biologia Vegetal, Caixa Postal 6109, 13.083-970 Campinas, SP, Brasil

2. Universidade Federal do Ceará, Centro de Ciências, Departamento de Biologia, 60455-970 Fortaleza, CE, Brasil

3. Autor para correspondência: rtbio@yahoo.com.br 
de informações do componente herbáceo na área do entorno do Parque das Dunas do Natal, este trabalho objetivou realizar o levantamento florístico deste táxon, visando contribuir para um melhor conhecimento da flora local e de fornecer informações que auxiliem em estudos futuros sobre Chamaecrista.

\section{Material e Métodos}

O Parque das Dunas de Natal (5'47'42'-5'52'03" S e $\left.35^{\circ} 12^{\prime} 34^{\prime \prime}-35^{\circ} 11^{\prime} 01^{\prime \prime} \mathrm{W}\right)$, localizado na região metropolitana do município de Natal (Figura 1), abrange uma área de 1.172 hectares de mata nativa sobre dunas (Freire 1990), sendo parte integrante da Reserva da Biosfera da Mata Atlântica.

Caracteriza-se pela predominância de espécies peculiares aos Tabuleiros Litorâneos, Floresta Atlântica e ainda das Caatingas (Freire 1990), que se desenvolvem sobre solos rasos do tipo Areias Quartzosas Marinhas Distróficas, com predominância de sedimentos recentes e Latossolos VermelhoAmarelo (SEPLAN 1985, Nunes 2000). O clima é do tipo tropical chuvoso com verão seco, com temperaturas médias anuais variando entre 22,6 a $29,2{ }^{\circ} \mathrm{C}$, e precipitação pluviométrica de 1.200 a $2.000 \mathrm{~mm}$, com período chuvoso entre junho e agosto (Tavares 1983, Nunes 2000).

As principais influências antrópicas no Parque das Dunas devem-se à presença de um anel viário que praticamente circunda toda a sua extensão e na porção sudoeste, da construção do campus Central da Universidade Federal do Rio Grande do Norte (UFRN) que abrange 123 hectares.
O campus da UFRN que no passado formava uma área contínua ao Parque das Dunas, atualmente se encontra separado deste apenas por uma rua (ca. de $30 \mathrm{~m}$ ) e sua vegetação original está totalmente descaracterizada, sendo constituída por várias espécies introduzidas como Delonix regia (Bojer ex Hook.) Raj. (flamboiant), Senna siamea (Lam.) H.S.Irwin \& Barneby (cássia), Licania rigida Benth. (oiticica), Cassuarina sp. (Casuarina), Cocos nucifera L. (Coco), entre outras. Tanto no entorno do Parque como no campus da UFRN, existe uma grande quantidade de espécies herbáceas, sendo Chamaecrista o gênero mais expressivo.

As excursões de campo foram realizadas no período de julho/2002 a agosto/2007, em todo o entorno do Parque Estadual das Dunas. Para as coletas e desidratação do material botânico, seguiu-se a metodologia de Bridson \& Forman (1998). Toda a coleção botânica resultante foi depositada no Herbário da UFRN e as duplicatas doadas a outras instituições nacionais.

A análise morfológica do material botânico foi baseada em exemplares obtidos em campo e coleções herborizadas pertencentes ao Herbário UFRN.

A identificação dos táxons foi feita através de bibliografias especializadas (Irwin \& Barneby 1982, Lewis 1987, Costa 1996, Conceição 2000) ou por comparação com materiais dos Herbários IPA, UFRN, UFP e PEUFR, cujos acrônimos estão de acordo com Holmgren et al. (1990).

Nas descrições adotou-se a terminologia de Radford et al. (1974) e Stearn (1992). Para designar os padrões de nervação e forma de fruto, adotou-se os termos propostos por Conceição (2000) e para a

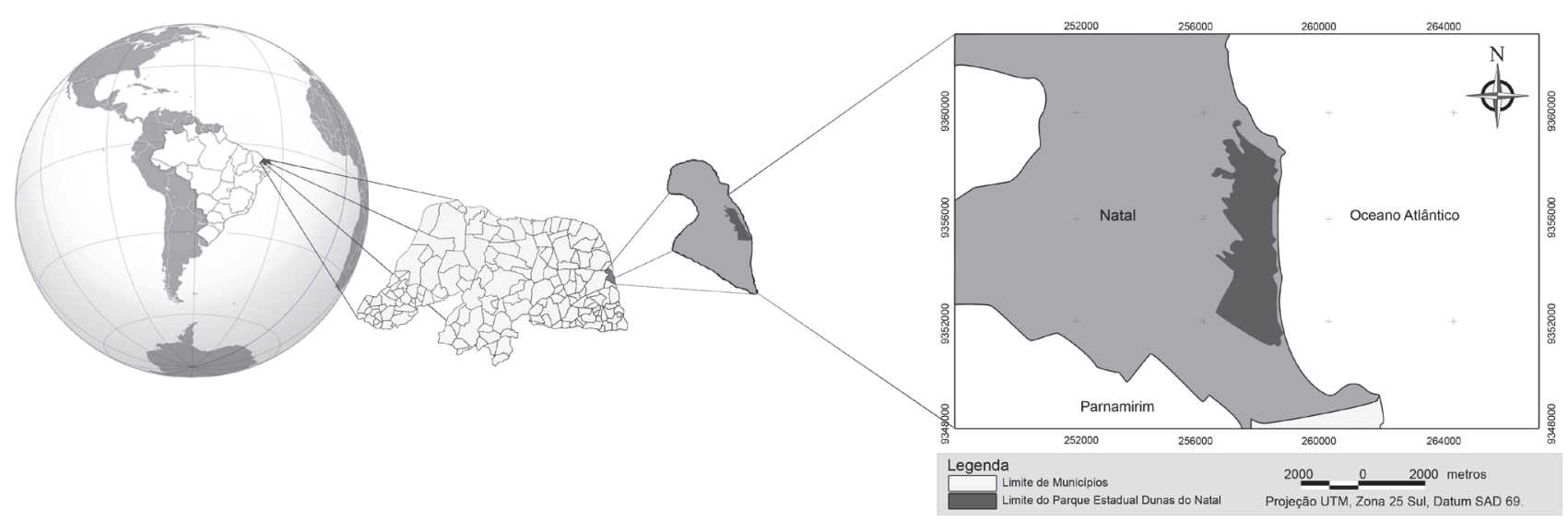

Figura 1. Mapa do Rio Grande do Norte indicando a localização do Parque Estadual das Dunas do Natal.

Figure 1 Map of the state of Rio Grande do Norte showing the Parque Estadual das Dunas de Natal. 
grafia dos nomes dos autores utilizou-se Brummitt \& Powell (1992). A confecção das pranchas ilustrativas foram realizadas com o auxílio de estereomicroscópio e câmara-clara Zeiss.

\section{Resultados e Discussão}

No levantamento foram registradas 10 espécies de Chamaecrista: C. calycioides (DC. ex Collad.) Greene var. calycioides, C. diphylla (L.) Greene, C. ensiformis (Vell.) H.S.Irwin \& Barneby var. ensiformis, C. flexuosa (L.) Greene var. flexuosa, C. hispidula (Vahl) H.S.Irwin \& Barneby, C. pilosa (L.) Greene var. luxurians (Benth.) H.S.Irwin \& Baneby, C. ramosa (Vog.) H.S.Irwin \& Barneby var. ramosa, C. rotundifolia (Pers.) Greene var. rotundifolia, C. serpens (L.) Greene var. serpens e C. supplex (Mart. ex Benth.) Britton \& Rose ex Britton \& Killip.
Chamaecrista Moench, Meth. Pl. Hort. Bot. Marburg: 272. 1794.

Árvores, arbustos, subarbustos ou ervas, anuais, bianuais ou perenes. Folhas alternas, paripinadas, compostas por 1 a 65 pares de folíolos membranáceos ou coriáceos; nervação palmada, paralela, pinada ou palmado-dimidiada; nectários extraflorais sésseis a estipitados, inseridos no pecíolo; fascículos com 1-muitas flores; bractéolas 1-2, persistentes; flores andróginas, zigomorfas ou assimétricas, 5 sépalas imbricadas, esverdeadas, às vezes avermelhadas quando jovens; 5 pétalas, heteromórficas ou homomórficas, amarelas a alaranjadas; androceu 5-10 estames férteis, anteras basifixas e mais longas que os filetes, com suturas laterais pubescentes a pilosas, deiscentes por poro apical ou curta fenda lateral; pistilo obliquamente divergente em relação aos estames; ovário súpero, unicarpelar, unilocular, híspido, velutino, puberulento; legumes lineares, oblongo-lianeares, glabro, híspido, velutino, tomentoso; sementes lisas ou pontuadas, esbranquiçadas a enegrecidas.

Chave para a identificação das espécies

1. Árvore; estípulas caducas; flores em racemos caulifloros C. ensiformes var. ensiformis

1. Subarbusto ou erva; estípulas presentes; flores isoladas ou em racemos nunca caulifloros

2. Flores em racemos terminais; folíolos com nervação pinada C. hispidula

2. Flores isoladas, axilares ou terminais; folíolos com nervação palmada ou paralela

3. Folhas com um par de folíolos

4. Tricomas dendríticos presentes entre a inserção dos folíolos; nectários ausentes no pecíolo; folíolos com nervação palmada C. rotundifolia var. rotundifolia

4. Tricomas dendríticos ausentes; nectários presentes no pecíolo; folíolos com nervação paralela C. diphylla

3. Folhas com mais de um par de folíolos

5. Subarbusto ereto a decumbente; ramos em "zig-zag"; nectários sésseis no pecíolo .. C. flexuosa var. flexuosa

5. Erva prostrada, decumbente ou ereta; ramos nunca em "zig-zag"; nectários estipitados no pecíolo

6. Pedicelo frutífero com 2-7 mm compr.

7. Erva decumbente; folhas com 9-12 pares de folíolos; estípulas lanceoladas . C. calycioides var. calycioides

7. Erva prostrada; folhas com 4-5 pares de folíolos; estípulas cordiformes C. supplex

6. Pedicelo frutífero com 19-33 mm compr.

8. Sépalas heteromórficas; folhas com 2 pares de folíolos C. ramosa var. ramosa

8. Sépalas homomórficas; folhas com 4-13 pares de folíolos

9. Estames 10; legume linear-oblongo C. serpens var. serpens

9. Estames 5; legume linear C. pilosa var. luxurians 
Chamaecrista calycioides (DC. ex Collad.) Greene var. calycioides, Pittonia 4: 32. 1899.

Figuras 2A-C

Erva decumbente, anual, 18-22 cm, densamente ramificada. Indumento hirsuto a seríceo nos ramos, estípulas, folhas, sépalas e frutos. Estípulas 2-4 × 1-2 $\mathrm{mm}$, lanceoladas. Folhas com 9-12 pares de folíolos; pecíolo 2-5 mm compr.; 1-2 nectários estipitados; folíolos 8-12 × 1,5-2 mm, lanceolados, membranáceos, ápice acuminado, base assimétrica, margem ciliada, nervação palmado-dimidiada. Flores isoladas, 7-14 mm compr., axilares; bractéolas 1-5 × 0,4-1,1 mm, lanceoladas a ovais; pedicelo $2-7 \mathrm{~mm}$ compr.; sépalas 5-7 × 1,3-3 mm, lanceoladas, homomórficas, verdes; pétalas 6-8 × 2-6 $\mathrm{mm}$, obovais, heteromórficas, amarelas; estames 10, 5-6 mm compr.; ovário 4-5 mm compr., híspido; estilete 4-6 mm compr., curvo. Legume 25-30 × 3-4 mm, elíptico, linear, híspido, marrom; pedicelo frutífero 2-7 mm compr. Sementes 1,8-2 × 0,8-1 mm, trapezóides, pontuadas, castanhas.

Material examinado: BRASIL. Rio GRAnde Do Norte: Natal, Parque Estadual das Dunas, dunas de Mãe Luiza, VII-1955, fr., S. Tavares 419 (UFPE); idem, Parque das Dunas, ca. 200 m antes do Imirá Plaza Hotel, sentido Praia dos Artistas/Ponta Negra, 5 49'11'S, 35¹1'00”'W, VII-2007, fl., fr., M.I.B. Loiola \& M. A. Loiola 1135 (UFRN); idem, Campus Central da UFRN, X-2002, fl., R.T. Queiroz 116 (UEFS, UFRN); idem, IV-2003, fl., fr., R.T. Queiroz 40 (UFRN); idem, VII-2005, fl., fr., R.T Queiroz 489 (UFRN); idem, X-2005, fl., fr., R.T. Queiroz 557

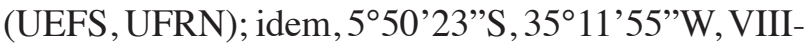
2007, fl., fr., M.I.B. Loiola 1224 (UFRN).

Chamaecrista calycioides é uma espécie facilmente reconhecida por ser uma erva decumbente, com folhas constituídas por 9-12 pares de folíolos, estípulas lanceoladas e flores isoladas. Diferencia-se das demais espécies estudadas especialmente por apresentar pedicelos florais e frutíferos muito curtos (2-5 mm e 2-7 mm de comprimento, respectivamente).

Irwin \& Barneby (1982) com base no número de estames, largura dos folíolos e tamanho do fruto reconheceram para esta espécie duas variedades: $C$. calycioides var. calycioides com folíolos relativamente largos, 8-10 estames e fruto linear e, $C$. calycioides var. lentiformis H.S.Irwin \& Barneby que apresenta folíolos estreitos, 3-5 estames e fruto oblongo. Na área de estudo foi encontrada a primeira variedade, que geralmente forma amplas populações e sua ocorrência está associada à outra espécie do gênero, C. serpens (L.) Greene var. serpens.

De acordo com Irwin \& Barneby (1982) este táxon foi registrado no México, Guiana Francesa, Venezuela, Brasil (Pará, Roraima, Rio Grande do Norte, Bahia, Goiás e São Paulo), Paraguai e Argentina, geralmente associada aos ambientes de savana e campos, frequentemente em solos arenosos e altitudes abaixo de $600 \mathrm{~m}$. No Rio Grande do Norte, esta espécie tem uma ampla distribuição ocorrendo desde o litoral (Natal) ao interior (região do Seridó), desenvolvendo-se em locais abertos.

Chamaecrista diphylla (L.) Greene, Pitonia 4: 28. 1899

Figuras 2D-F

Erva ereta, anual, 20-60 $\mathrm{cm}$, pouco ramificada. Indumento híspido nas estípulas e pecíolos. Estípulas 7-15 × 3,5-6 mm, lanceoladas. Folhas com um par de folíolos; pecíolo 5-8 mm compr.; 2 nectários estipitados; folíolos 14-22 × 8-14 mm, obovais, membranáceos, ápice obtuso, base assimétrica, margem inteira; nervação paralela. Flores isoladas ou reunidas em fascículos com 3 flores, 5-8 mm compr., axilares; bractéolas 1-2 × 0,2-0,3 mm, lanceoladas; pedicelo 10-34 mm compr.; sépalas 5,4-7 × 1,2-2 $\mathrm{mm}$, lanceoladas, heteromórficas, verde-claras; pétalas 4-8 × 4-2 mm, oblongas, heteromórficas, amarelas; estames 10, 3-5mm compr.; ovário 4-6 mm compr., velutino; estilete 3-4 mm compr., curvo. Legume 25$30 \times 4-5 \mathrm{~mm}$, linear-oblongo, escassamente velutino, amarronzado; pedicelo frutífero 15-34 mm compr. Sementes 2-3 × 0,8-1 mm, trapezóides, faveoladas, enegrecidas.

Material examinado: BRASIL. Rio GRANDE do NorTE: Natal, Campus da UFRN, VI-2003, fl., fr., R.T. Queiroz 42 (UFRN); idem, VIII-2002, fl., fr., R.T. Queiroz 114 (UFRN); idem, VII-2005, fl., fr., R.T. Queiroz 491 (UEFS, UFRN).

Chamaecrista diphylla pode facilmente ser confundida com $C$. rotundifolia var. rotundifolia, especialmente, por ambas apresentarem apenas um par de folíolos. Porém estas duas espécies podem ser prontamente separadas quanto ao hábito, distribuição dos tricomas, tipo de venação e forma das sementes. C. diphylla é uma erva ereta, com tricomas apenas nas estípulas e pecíolo e sementes retangulares, enquanto $C$. rotundifolia var. rotundifolia é uma erva decumbente com tricomas em todos as suas 
porções vegetativas, tendo tricomas dendríticos entre o par de folíolos e sementes rombóides. As duas espécies podem também ser diferenciadas com base na presença de nectários, $C$. diphylla possui dois nectários e C.rotundifolia var. rotundifolia não apresenta nectários.

De acordo com Irwin \& Barneby (1982), C. diphylla tem uma ampla distribuição e foi registrada desde o México, Caribe e América Central até a América do Sul. No Brasil, ocorre nas Regiões: Norte (Amazonas); Centro-Oeste (Goiás e Mato Grosso) e Sudeste (Minas Gerais). Chamescrista diphylla é citada pela primeira vez para o estado do Rio Grande do Norte.

$\mathrm{Na}$ área de estudo, esta espécie ocorre freqüentemente em solos arenosos e levemente sombreados, formando grandes populações.

Chamaecrista ensiformis (Vell.) H.S.Irwin \& Barneby var. ensiformis, Mem. New York Bot. Gard. 35: 642. 1982.

Figuras 2G-H

Árvore 5-7 m, glabra nas porções vegetativas. Estípulas caducas. Pecíolo 22-31 mm compr.; 2 nectários sésseis entre as inserções adaxiais de cada par de folíolos. Folhas com 2-3 pares de folíolos; pecíolo 1,4-2 cm compr.; nectários sésseis; folíolos 35$70 \times 25-34 \mathrm{~mm}$, oblongo-lanceolados, coriáceos, ápice agudo, base assimétrica, margem inteira; nervação pinada. Flores em racemos caulifloros, 12-16 mm compr.; bractéolas $0,1 \times 0,1 \mathrm{~mm}$, acicular; pedicelo 25-26 mm compr.; sépalas 4-6 × 2-2,5 mm, oblongoabovais, homomórficas; esverdeadas; pétalas 11-15× 7-11 mm, obovais, homomórficas, amarelas. Estames 10, 4-5 mm compr. Ovário 2-3 mm, puberulento; estilete 5-6 mm compr., curvo. Pedicelo frutífero 10$14 \mathrm{~mm}$ compr. Legume $95-122 \times 11-13 \mathrm{~mm}$, linear, glabro, verde (imaturo) a marrom (maduro). Sementes não observadas.

Material examinado: BRASIL. Rio GRANDE Do NoRTE: Natal, Campus da UFRN, VIII-2002, fl., fr., R.T. Queiroz 22 (UFRN); idem, V-2003, fl., fr., R.T. Queiroz 129 (UFRN); Parque das Dunas, 550'30"S, $35^{\circ} 11$ " 42 ”'W, VIII-2007, fl., M.I.B. Loiola et al. 1120 (UFRN).

Chamaecrista ensiformis diferencia-se das demais espécies, por ser a única que possui porte arbóreo (podendo atingir até sete metros de altura), racemos caulifloros e estípulas caducas.
Irwin \& Barneby (1982) com base no número de pares de folíolos, tipo de indumento dos ramos e folíolos e área de distribuição geográfica reconheceram para esta espécie três variedades: $C$. ensiformis var. ensiformis que apresentava 3-5 pares de folíolos, indumento escassamente puberulento ou glabro nos ramos e folíolos e ampla distribuição geográfica; $C$. ensiformis var. maranonica (H.S.Irwin) H.S.Irwin \& Barneby também com 3-5 pares de folíolos, mas com ramos e folíolos densamente pilosos, ocorrendo no Maranhão, Pará e Goiás e C. ensiformis var. plurifoliolata (Hoehne) H.S.Irwin \& Barneby com 5-8 pares de folíolos e distribuição no interior do Rio de Janeiro e sul da Bahia.

$\mathrm{Na}$ área de estudo esta espécie apresentou período de floração variado, porém, frequentemente, há predominância de flores nos meses de agosto a novembro e estas possuem um forte odor, que de acordo com Costa (1996) é um caráter raro do gênero. Vale ressaltar que embora tenha ocorrido formação do legume, não foi observado desenvolvimento de sementes. Este fato deve-se, provavelmente, à presença de um pequeno inseto que deposita seus ovos no interior dos frutos, cujas larvas crescem alimentando-se de toda a estrutura interna destes.

Esta espécie tem distribuição restrita ao Brasil (Filardi et al. 2007). De acordo com Costa (1996), foi registrada nas Regiões Nordeste (Maranhão, Rio Grande do Norte, Pernambuco e Bahia), Centro Oeste (Goiás) e Sudeste (Minas Gerais, São Paulo, Rio de Janeiro e Espírito Santo). No Rio Grande do Norte, C. ensiformis está bem representada em ambientes de restinga e tabuleiros costeiros (Cestaro 2002), ocorrendo sempre associada às áreas mais abertas, como clareiras e bordas de mata.

Chamaecrista flexuosa (L.) Greene var. flexuosa, Pittonia 4: 27. 1899.

Figuras 2I-J

Subarbusto ereto a decumbente, bianual, com até $40 \mathrm{~cm}$, pouco ramificado; ramos em zig-zag, glabros. Estípulas 6-10 × 3-7 mm, lanceoladas a ovais. Folhas com 48-65 pares de folíolos; pecíolo 1-3 mm compr., 1-2 nectários sésseis; folíolos 4-6 × 1-1,5 mm, linearoblongos, membranáceos, ápice mucronado, base assimétrica, margem ciliada; nervação palmadodimidiada. Flores isoladas, 14-15 mm, axilares ou terminais; bractéolas 0,5-1 ×0,2-0,4 mm, lanceoladas a ovais; pedicelo 2,5-3,2 cm compr.; sépalas 4-6 $\times$ 2-3 mm, forma, homomórficas, lanceoladas, com 
tricomas na face dorsal, verdes; pétalas 14-18 × 7-9 $\mathrm{mm}$, obovais, heteromórficas, alaranjadas quando jovens e amarelas na maturidade; estames 10, 7-9 $\times 0,5-0,8 \mathrm{~mm}$, evidentes quando as flores estão em antese; ovário 4-6 mm compr., velutino; estilete 3-6 mm compr., curvo. Legume 25-30 × 3-4 mm, elíptico, linear, levemente pubérulo, amarronzado; pedicelo frutífero 15-22 mm compr. Sementes 2,5-3 × 5-2 mm, trapezóides, faveoladas, variando de esbranquiçadas a amarronzadas.

Material examinado: BRASIL. RIO GRANDE DO NORTE: Natal, Campus da UFRN, IX-2002, fl. fr., R.T. Queiroz 27 (UFRN); idem, IV-2003, fl. fr. R.T. Queiroz 117 (UFRN); idem, VII-2005, fl. fr., R.T. Queiroz 487 (UEFS, UFRN); idem, X-2005, fl. fr., R.T. Queiroz 548 (UEFS, UFRN); idem, Parque das Dunas, em frente ao NUPEG, 5'50'36"'S, 35'11'43"W, VI-2007, fl. fr., M.I.B. Loiola et al. 1053 (UFRN); idem, Ca. $200 \mathrm{~m}$ antes do Imirizá Plaza Hotel, sentido Praia dos artistas/ Ponta Negra, 5'49'11'S, 35¹1'00”W, VII-2007, fl., fr., M.I.B. Loiola \& M.A. Loiola 1134 (UFRN); idem, VIII-2007, 5'50'30"S, 35'11"42"W, M.I.B. Loiola et al. 1196 (UFRN).

Esta espécie pode ser facilmente reconhecida por ser a única, entre as espécies estudadas, que apresenta os ramos em "zig-zag", folhas com numerosos pares de folíolos (48-65) e nectários sésseis.

No tratamento proposto Irwin \& Barneby (1982) foram reconhecidas duas variedades para este táxon: C. flexuosa var.flexuosa, caracterizada por apresentar folhas com 25-65 pares de folíolos, fruto com 4-7 cm compr. e 10-22 sementes e C. flexuosa var. texana (Bckley) H.S.Irwin \& Barneby, com folhas possuindo 9-20 pares de folíolos, fruto com 2,5-4,7 cm de comprimento. e 8 a 12 sementes.

De acordo com Irwin \& Barneby (1982), esta espécie foi registrada nas seguintes Regiões brasileiras: Norte (Amazonas, Roraima, Pará), Nordeste (Maranhão, Pernambuco, Paraíba e Rio Grande do Norte), Sudeste (Minas Gerais e São Paulo) e Centro Oeste (Goiás e Mato Grosso). Camargo e Miotto (2004) registraram também este táxon para o Rio Grande do Sul. A espécie habita locais abertos, sendo nativa em areias marítimas e margens de estradas, geralmente abaixo de $450 \mathrm{~m}$ de altitude podendo atingir até $1300 \mathrm{~m}$. É citada como planta daninha, freqüentemente invadindo plantações, porém servindo de forragem durante o período de estiagem (Lorenzi 2000).
Chamaecrista flexuosa var.flexuosa foi encontrada na área de estudo tanto em locais sombreados, como abertos com alta luminosidade. Floresce durante todo $\mathrm{o}$ ano e as flores permanecem abertas durante um curto período do dia.

Chamaecrista hispidula (Vahl) H.S.Irwin \& Barneby, Mem. New York Bot. Gard. 35: 661. 1982.

Figuras $2 \mathrm{~K}-\mathrm{L}$

Erva decumbente, bianual, 0,3-0,5 m. Indumento híspido-glanduloso nos ramos, pecíolo, pedicelo, sépalas e frutos. Estípulas 1,5-2 × 0,2-0,5 mm, aciculares. Folhas com 2 pares de folíolos; pecíolo 17-33 mm compr., nectários ausentes; folíolos 12-30 $\times$ 9-23 mm, obovais a orbiculares, membranáceos, ápice arredondado, base cuneada, margem ciliada; nervação pinada. Inflorescências em racemos terminais, constituídas por 5-14 flores. Flores 8-20 mm compr.; bractéolas 1-1,5 × 0,1-0,4 mm aciculares; pedicelo 14-20 mm compr.; sépalas 12-15 × 3-5 mm, lanceoladas, heteromórficas, verde-claras, podendo apresentar ainda a porção central vinácea, com tricomas na face dorsal; pétalas 14-22 × 7-12 mm, oblongas, heteromórficas, amarelas; estames 10, 6-8 mm; ovário 4-5 mm compr., velutino; estilete 15-16 $\mathrm{mm}$ compr., curvo. Legume 33-47 × 5-9 mm, linearoblongo, híspido, amarronzado; pedicelo frutífero 14$22 \mathrm{~mm}$ compr. Sementes 3-4 × 1-2 mm, trapezóides, faveoladas, enegrecidas.

Material examinado: BRASIL. Rio GRANDE do NoRTE: Natal, Campus da UFRN, 5'50'17S, 35'11'47'W; X-2002, fl., fr., R.T. Queiroz 25 (UFRN); idem, IV-2003, fl., fr., R.T. Queiroz 124 (UFRN); idem, $5^{\circ} 50^{\prime} 26^{\prime}$ 'S, 35 $12^{\circ}$ '00'W, IV-2005, fl., fr., R.T. Queiroz

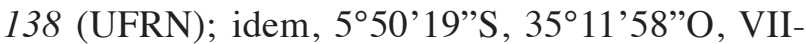
2005, fl., fr., R.T. Queiroz 494 (UEFS, UFRN); idem, 5'50"28”'S, 35¹1'51”O, X-2005, fl., fr., R.T. Queiroz 552 (UFRN); idem, Parque das Dunas, Via Costeira, próximo ao Restaurante Tábua de Carnes, $5^{\circ} 47^{\prime} 37^{\prime}$ 'S, $35^{\circ} 11^{\prime} 05^{\prime \prime} \mathrm{W}, \mathrm{VII}-2007$, fl., M.I.B. Loiola \& M.A. Loiola 1121 (UFRN); idem, limite entre o Parque das Dunas e o Colégio Henrique Castriciano, 547'37’'S, $35^{\circ} 11$ '35”W, VIII-2007, fl., fr., M.I.B. Loiola \& M.A. Loiola 1222 (UFRN).

Chamaecrista hispidula é um táxon facilmente reconhecido por apresentar tricomas híspidosglandulosos especialmente nas porções vegetativas (caule e ramos) e reprodutivas (pedicelo e sépalas); pedicelos longos (14-20 mm de comprimento); 


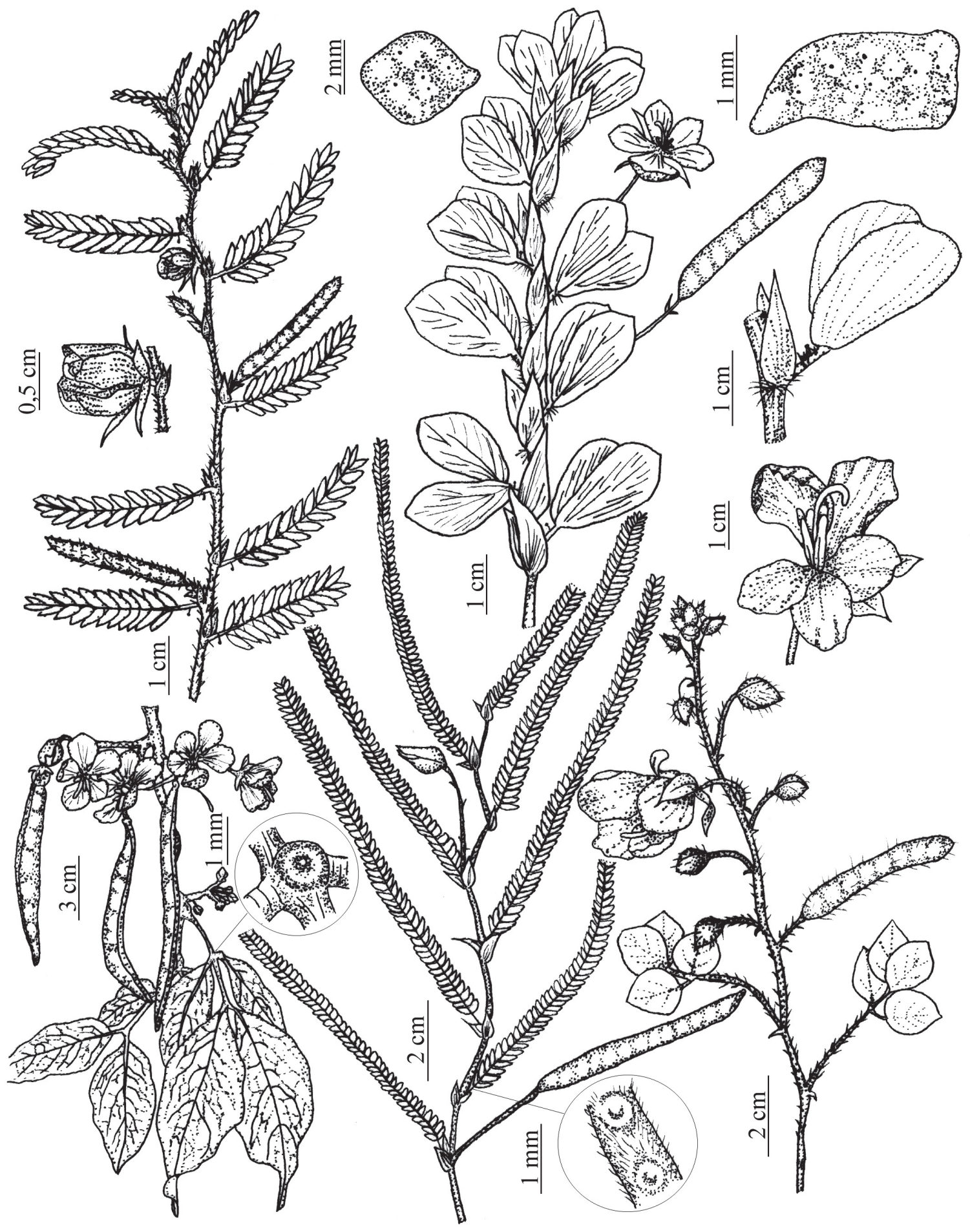

Figura 2. A-C. Chamecrista calycioides var. calycioides. A. Ramo com flor e frutos. B. Flor. C. Semente. D-F. C.diphylla. D. Ramo com flor e fruto. E. Detalhe da folha e estípulas. F. Semente. G-H. C. ensiformis var. ensiformis. G. Ramo com flores e frutos. H. Detalhe do nectário séssil. I-J. C. flexuosa var. flexuosa. I. Ramo com botões e fruto. J. Detalhe do nectário séssil entre a inserção abaxial dos folíolos. K-L. C. hispidula. K. Ramo com botões flor e fruto. L. Flor.

Figure 2. A-C. Chamecrista calycioides var. calycioides. A. Branch with flower and fruits. B. Flower. C. Seed. D-F. C. diphylla. D. Branch with flower and fruit. E. Detail of leaf and stipule. F. Seed. G-H. C. ensiformis var. ensiformis. G. Branch with flower and fruits. H. Detail of sessile nectary. I-J. C. flexuosa var. flexuosa. I. Branch with buds and fruit. J. Detail of sessile nectary between the abaxial insertion of the leaflets. K-L. C. hispidula. K. Branch with buds, flower and fruit. L. Flower. 
inflorescência terminal, constituída por flores grandes, quando comparada com as demais espécies.

Foi citada para o Brasil por Bentham (1870) nas Regiões Sudeste (Espírito Santo e Minas Gerais); Centro-Oeste (Goiás) e Nordeste (Piauí, Ceará e Bahia). De acordo com Lewis (1987) esta espécie ocorre geralmente em ambientes de restinga e solos arenosos.

Chamaecrista pilosa (L.) Greene var. luxurians (Benth.) H.S.Irwin \& Barneby, Mem. New York Bot. Gard. 25(2): 720. 1982.

Figuras 3A-B

Erva ereta, anual, 42-50 cm, densamente ramificada. Indumento hirsuto a densamente hirsuto nos ramos e margens das estípulas. Estípulas 6-8 $\times 2-2,5 \mathrm{~mm}$, lanceoladas. Folhas com 8-10 pares de folíolos; pecíolo 1-3 mm compr., 2-4 nectários estipitados; folíolos 10-15 × 2,5-3,5 mm, oblongos, membranáceos, ápice mucronado, base assimétrica, margem ciliada, glabros; nervação palmada. Flores 5-7 mm compr.; bractéolas 2-3 × 0,2-0,4 mm, aciculares; pedicelo 24-28 mm compr.; sépalas 3-5 × 0,5-1 mm, lanceoladas, homomórficas, verde-claras; pétalas 4-5 $\times$ 2-3 mm, obovais, heteromórficas, amarelas; estames 5, com 3-4 mm compr.; ovário 3-4 mm compr., velutino; estilete 2-3 mm compr., curvo. Legume 40-42 × 4-5 $\mathrm{mm}$, linear, escassamente tomentoso, amarronzado; pedicelo frutífero $28-33 \mathrm{~mm}$ compr. Sementes 2, 1-2,3 × 1,2-1,5 mm, trapezóides, faveoladas, esbranquiçadas.

Material examinado: BRASIL. RIo GRANDE DO NoRTE: Natal, Campus da UFRN, VIII-2002, fl., fr., R.T. Queiroz 19 (UFRN); idem, X-2005, fl., fr., R.T. Queiroz 561 (UEFS, UFRN).

Chamaecrista pilosa var. luxurians distingue-se das demais por ser uma erva ereta, com flores pequenas (5-7 mm de comprimento) e possuir apenas cinco estames. Assemelha-se a $C$. serpens var. serpens por ambas apresentarem folhas com cerca de oito pares de folíolos e flores pequenas. Entretanto, C. pilosa var. luxurians pode ser diferenciada de $C$. serpens var. serpens pelas seguintes características: erva ereta (vs. erva prostrada em C. serpens var. serpens), cinco estames (vs. 10 estames) e fruto linear (vs. fruto linear-oblongo).

Este táxon foi registrado nos Estados do Tocantins, Goiás, Maranhão, Bahia, Ceará (Irwin \& Barneby 1982). Na área de estudo apresenta distribuição restrita, desenvolvendo-se em solos arenosos e formando pequenas populações. Chamaecrista pilosa var. luxurianus está sendo citada pela primeira vez para o estado do Rio Grande do Norte.

Chamaecrista ramosa (Vog.) H.S.Irwin \& Barneby var. ramosa, Mem. New York Bot. Gard. 35: 884. 1982.

Figuras 3C-D

Subarbusto decumbente, bianual, 10-20 cm, densamente ramificado, glabro. Estípulas 5-7 $\times$ 3-4 mm, lanceoladas a cordiformes. Folhas com 2 pares de folíolos; pecíolo 1-2 mm compr., 1-2 nectários estipitados; folíolos 8-11 × 4,1-5 mm, oblongos, membranáceos, ápice obtuso, base cuneada, margem inteira, glabros; nervação paralela. Flores isoladas, 15-17 mm compr.; bractéolas 2-2,5 × 1-1,5 mm, lanceoladas; pedicelo 20-25 mm compr.; sépalas 10-14 × 3-4 mm, oblongas, heteromórficas, vermelho-vináceas; pétalas 10-14 × 3-4 mm, obovais, heteromórficas, amarelas; estames 10, sésseis; ovário 4-5 mm compr., estrigoso; estilete 5-10 mm, curvo. Legume 26-35 × 5-6 mm, linear, escassamente estrigoso, amarronzado; pedicelo frutífero $20-22 \mathrm{~mm}$ compr. Sementes 3-4 × 1-1,5 mm, ovais, faveoladas, enegrecidas.

Material examinado: BRASIL. Rio GRANDE Do Norte: Natal, Campus da UFRN, X-2002, fl., fr., R.T. Queiroz 26 (UFRN); idem, IV-2003, fl., fr., R.T. Queiroz 118 (UFRN); idem, IV-2005, fl., fr., R.T. Queiroz 139 (UEFS, UFRN); idem, VII-2005, fl., fr., R.T. Queiroz 486 (UEFS, UFRN); idem, VII-2005, fl., fr., R.T. Queiroz 546 (UFRN); idem, VII-2005, fl., fr., R.T. Queiroz 495 (UEFS, UFRN); idem, X-2005, fl., fr., R.T. Queiroz 551 (UFRN); Parque das Dunas, 5'50'30”'S, 35¹1'42”'W, VIII-2007, fl., fr., M.I.B. Loiola et al. 1198 (UFRN).

Chamaecrista ramosa var. ramosa caracterizase por ser um subarbusto decumbente, com folhas constituídas por dois pares de folíolos, estames sésseis e sépalas vermelho-vináceas. No tratamento taxonômico proposto por Irwin \& Barneby (1982) foram reconhecidas seis variedades para esta espécie com base principalmente na presença de estípulas sésseis ou estipitadas, distância entre os pares de folíolos e tamanho dos pecíolos.

Possui uma ampla distribuição na América do Sul, tendo sido registrada na Bolívia, Venezuela, Guiana e no Brasil (Irwin \& Barneby 1982). Em território 
brasileiro ocorre em toda a Região Sudeste (Espírito Santo, Minas Gerais, Rio de Janeiro e São Paulo), Norte (Pará e Roraima) e em toda a costa da Região Nordeste (Irwin \& Barneby 1982), em ambientes de savana, dunas costeiras, restinga e área de transição Cerrado-Caatinga.

Esta espécie tem uma ampla distribuição em toda área de estudo desenvolvendo-se principalmente em locais arenosos.

Chamaecrista rotundifolia (Pers.) Greene var. rotundifolia, Pittonia 4: 31.1989.

Figuras 3E-F

Erva decumbente, $20-30 \mathrm{~cm}$, anual, ramificada. Indumento hirsuto a híspido nos ramos, pecíolos, botões e face externa das sépalas. Estípulas 7-12 $\times$ 4-5 mm, ovais com ápice acuminado, assimétricas. Folhas com um par de folíolos, entre os quais se observa um tricoma dendrítico; pecíolo $2-4 \mathrm{~mm}$ compr., nectários ausentes; folíolos 14-32 × 7-26 mm, oblongos a obovais, membranáceos, ápice obtuso, base assimétrica, margem inteira; nervação palmada. Flores isoladas, 5-6 mm compr., axilares; bractéolas 0,5-3 $\times$ 1-1,5 mm lanceoladas; pedicelo 15-20 mm compr.; sépalas 4-6 × 2-4 mm, lanceoladas, homomórficas, esverdeadas, com tricomas dorsalmente; pétalas 4-5 $\times$ 2-4 mm, oval-oblongas, heteromórficas, amarelas; estames 5, com 3-5 mm compr.; ovário 3-3,5 mm, velutino; estilete 1,5-4 mm, curvo. Legume 32-35 $\times 35-40 \mathrm{~mm}$, linear, escassamente puberulento, amarronzado; pedicelo frutífero $24-26 \mathrm{~mm}$ compr. Sementes 1-2 × 1-1,5 mm, trapezóides, faveoladas, esbranquiçadas.

Material examinado: BRASIL. Rio GRANDE Do NoRTE: Natal, Campus da UFRN, X-2002, fl., fr., R.T. Queiroz 115 (UFRN); idem, fl., fr., VII-2005, R.T. Queiroz 488 (UEFS, UFRN); X-2005, fl., fr., R.T. Queiroz 549 (UFRN); idem, V-2006, fl., fr., R.T. Queiroz 874 (UEFS, UFRN).

No tratamento apresentado por Irwin \& Barneby (1982) foram reconhecidas duas variedades para esta espécie: $C$. rotundifolia var. rotundifolia e $C$. rotundifolia var. grandiflora (Benth.) H.S.Irwin \& Barneby. A primeira caracteriza-se por apresentar flores relativamente pequenas, pétalas com três a sete mm de comprimento e quatro a cinco anteras férteis, enquanto a segunda, apresenta flores maiores, pétalas com sete a $17 \mathrm{~mm}$ de comprimento e cinco a sete anteras férteis.
Chamaecrista rotundifolia var. rotundifolia assemelha a $C$. diphylla, por ambas apresentarem um par de folíolos. Entretanto, estas duas espécies podem ser diferenciadas quanto ao hábito, distribuição dos tricomas, tipo de venação e nectários. As características que separam estes dois táxons já foram mencionadas na discussão de $C$. diphylla .

De acordo com Irwin \& Barneby (1982), Chamaecrista rotundifolia var. rotundifolia está bem distribuída na América Central e América do Sul, geralmente em ambientes de savanas, associada a locais abertos e iluminados, terrenos baldios, beiras de estradas e florestas perturbadas. No Brasil ocorre na Região Norte (Amazonas, Rondônia, Roraima e Tocantins); Nordeste, (Maranhão); Sudeste, (Rio de Janeiro e São Paulo); Centro-Oeste (Mato Grosso e Goiás) e Sul (Paraná). Camargo e Miotto (2004) registraram este táxon no Rio Grande do Sul. Constitui uma nova citação para o Estado do Rio Grande do Norte.

É indicada por Lorenzi (2000) como erva daninha em gramados e pastagens no Brasil.

Chamaecrista serpens (L.) Greene var. serpens, Pittonia 4: 29. 1899.

Figuras 3G-I

Erva prostrada, anual, 5-8 $\mathrm{cm}$, ramificada. Indumento esparsamente hirsuto nos ramos e pecíolos. Estípulas 2-3 × 1-2 mm, triangulares. Folhas com 4-8 pares de folíolos; pecíolo 1-3 mm compr., 1-3 nectários estipitados na base; folíolos 5-12 × 2-4 mm, oblanceolados, membranáceos, ápice mucronado, base assimétrica, margem ciliada, glabros; nervação palmada. Flores isoladas, 5-7 mm compr., axilares; bractéolas 1,5-2 × 0,2-0,5 mm, triangulares; pedicelo 15-22 mm compr.; sépalas 4-6 × 1-3 mm, deltóides, homomórficas, com tricomas na face dorsal, verdeclaras; pétalas 4-6 × 2-3 mm, obovais, heteromórficas, amarelas; estames 10, 4-5 mm compr.; ovário 3-5 $\mathrm{mm}$ compr., tomentoso; estilete $4-5 \mathrm{~mm}$ compr., curvo. Legume $20-40 \times 3,5-4 \mathrm{~mm}$, linear-oblongo, escassamente tomentoso, amarronzado; pedicelo frutífero 19-30 mm compr. Sementes 1,5-2 × 1-1,5 $\mathrm{mm}$, trapezóides, esbranquiçadas, faveoladas.

Material examinado: BRASIL. Rio GRANDE Do NorTE: Natal, Campus da UFRN, VIII-2002, fl., fr. R.T. Queiroz, 18 (UFRN); idem, X-2003, fl., fr., R.T. Queiroz 28 (UFRN); idem, VII-2005, fl., fr., R.T. Queiroz 490 (UEFS, UFRN); idem, Parque das Dunas, limite entre o Parque das Dunas e o Colégio Henrique 
Castriciano, 547'37'S, 35¹1'35'W, VIII-2007, fl., fr., M.I.B. Loiola \& M.A. Loiola 1223 (UFRN).

No tratamento taxonômico de Irwin \& Barneby (1982) foram reconhecidas sete variedades com base no número de folíolos, variação do tamanho das flores, pétalas e folíolos, tipo de venação, tamanho das estípulas e presença ou ausência de glândulas sésseis ou estipitadas.

Este táxon é similar a C. pilosa var. luxurians, no entanto, podem ser facilmente distintos por caracteres já mencionados na discussão de $C$. pilosa var. luxurians.

De acordo com Irwin \& Barneby (1982) $C$. serpens var. serpens pode ser encontrada na América Central e América do Sul. Em território brasileiro se distribui na Região Norte (Pará, Roraima), Nordeste (Maranhão, Rio Grande do Norte, Pernambuco e Bahia), Centro Oeste (Mato Grosso e Goiás) e Sudeste (Minas Gerais e São Paulo). Habita preferencialmente as savanas, no entanto, ocorre freqüentemente nas margens de estradas e gramados, estando geralmente associada a solos arenosos próximo ao litoral.

Chamaecrista supplex (Mart. ex Benth.) Britton \& Rose ex Britton \& Killip, Ann. New York Acad. Sci. 35: 185. 1936.

Figuras 3J-L

Erva prostrada, anual, 5-9 cm, densamente ramificada. Indumento hirsuto nos ramos, folhas, pedicelos, sépalas e frutos. Estípulas 2-4 × 1,5-2 $\mathrm{mm}$, cordiformes. Folhas com 4-5 pares de folíolos; pecíolo 2-4 mm compr., 1 nectário estipitado; folíolos 4-6 × 1,2 mm, oblongos, membranáceos, ápice agudo, base assimétrica, margem ciliada; nervação palmadodimidiada. Flores isoladas, 4-5 mm compr., axilares; bractéolas 1-1,5 × 0,1-0,3 mm, lanceoladas; pedicelo 5-7 mm compr.; sépalas 4-5 × 1-1,5 mm, lanceoladas, heteromórficas, esverdeadas; pétalas 3-4 × 1-3 mm, obovais, heteromórficas, amarelas; estames 5 , com 1,5-2 × 0,5-0,8 mm; ovário 1,5-2 mm compr., viloso; estilete 2-3 mm compr., curvo. Legume 10-12 × 2-3 $\mathrm{mm}$, linear-oblongo, hirsuto, amarronzado; pedicelo frutífero 5-7 mm compr. Sementes 1,2-1,5 × 1-2 mm, quadradas, esbranquiçadas.

Material examinado: BRASIL. RIo GRANDE do NoRTE: Natal, Campus da UFRN, X-2003, fl., fr., R.T. Queiroz 43 (UFRN); idem, X-2005, fl., fr., R.T. Queiroz 546 (UFRN).

Chamaecrista supplex caracteriza-se por apresentar flores pequenas (4-5 mm comprimento) e cinco estames. Outra característica marcante desta espécie são os frutos hirsutos, que geralmente ficam em contato com o solo.

Segundo Irwin \& Barneby (1982), esta espécie foi registrada nos estados do Maranhão, Ceará, Pernambuco, Bahia, Rio de Janeiro, Minas Gerais e Goiás, Amazonas, Pará e Tocantins, em ambiente de cerrado, caatinga, capoeira, campo ou ao longo de estradas. Na área de estudo, os indivíduos de $C$. supplex possuem distribuição restrita, ocorrendo geralmente associados a solos avermelhados. Constitui nova citação para o Rio Grande do Norte.

O gênero Chamaecrista está bem representado na área de estudo, sendo que dos dez táxons registrados, quatro são novas citações para o Estado do Rio Grande do Norte: Chamaecrista diphylla, C. pilosa var. luxurians, C. rotundifolia var. e C. supplex. Dentre as espécies estudadas, Chamaecrista hispidula e C. ramosa var. ramosa foram as que apresentaram distribuição mais ampla na área de estudo; já $C$. supplex apresentou a distribuição mais restrita. As características mais importantes para a separação dos táxons foram o tipo de hábito, número de folíolos, tipo de inflorescência e tamanho dos pedicelos florais e frutíferos.

Esse estudo apesar de pontual vem acrescentar informações para o conhecimento da flora herbácea potiguar e especialmente do gênero Chamaecrista.

\section{Agradecimentos}

Este trabalhoé parte da monografia de bacharelado do primeiro autor. Os autores agradecem ao Dr. Luciano Paganucci da Universidade Estadual de Feira de Santana-BA, pela confirmação da identidade dos táxons; Jeniffer Medeiros pela finalização das pranchas ilustrativas e Dr. Márcio Zikán Cardoso, da Universidade Federal do Rio Grande do Norte, pela elaboração do Abstract.

\section{Literatura citada}

Araújo, F.F., Sampaio, E.V.S.B., Figueiredo, M.A. \& Rodal, M.J.N. 1998. Composição florística da vegetação de carrasco, Novo Oriente, CE. Revista Brasileira de Botânica 21: 105-116.

Almeida Jr., E.B., Zickel, C.S. \& Pimentel, R.M.M. 2006. Caracterização e espectro biológico da vegetação do litoral arenosso do Rio Grande do Norte. Revista de Geografia 23: 45-58.

Bridson, D. \& Forman, L. 1998. The herbarium hand book. 3 ed. Royal Botanic Gardens, Kew. 


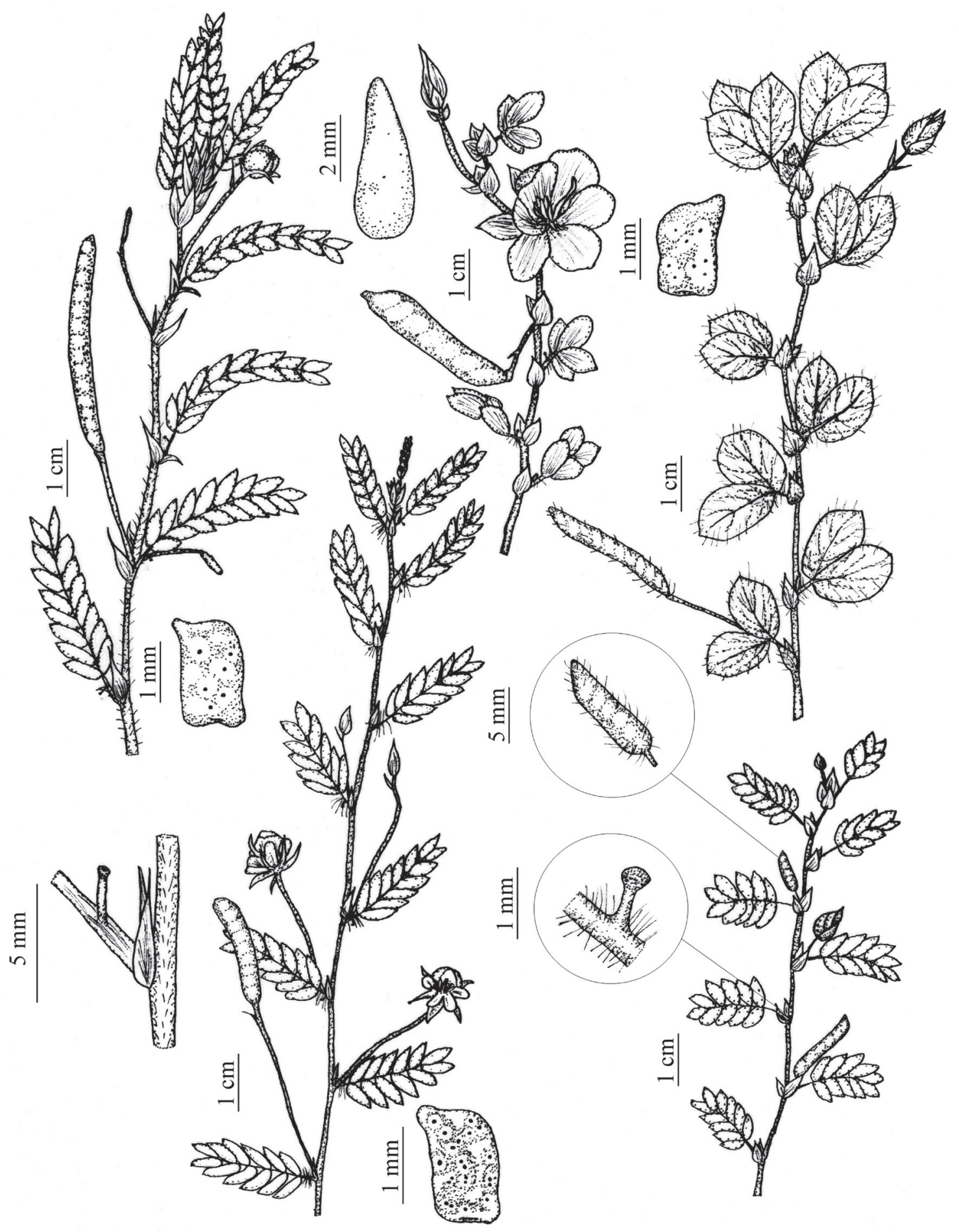

Figura 3. A-B. Chamaecrista pilosa var. luxurians. A. Ramo com flor e fruto. B. Semente. C-D. C. ramosa var. ramosa. C. Ramo com flor e fruto. D. Semente. E-F. C. rotundifolia var. rotundifolia. E. Ramo com flor e fruto. F. Semente. G-I. C. serpens var. serpens. G. Ramo com flor e fruto. H. Detalhe das estípulas e pecíolo com nectário estipitado. I. Semente. J-L. C. supplex. J. Ramo com fruto. K. Detalhe do pecíolo com nectário estipitado. L. Fruto.

Figura 3. A-B. Chamaecrista pilosa var. luxurians. A. Branch with flower and fruit. B. Seed. C-D. C. ramosa var. ramosa. C. Branch with flower and fruit. D. Seed. E-F. C. rotundifolia var. rotundifolia. E. Branch with flower and fruit. F. Seed. G-I. C. serpens var. serpens. G. Branch with flower and fruit. H. Detail of stipules and nectary sessile in petiole. I. Semente. J-L. C. supplex. J. Branch with fruit. K. Detail of petiole with stipitate nectary. L. Fruit. 
Brito, A.E.R.M., Madeira, Z.R., Costa, F.A.P., Nunes, E.P., Matias, L.Q. \& Silva, F.H.M. 2006. Vegetação costeira do nordeste semi-árido-guia ilustrado. Edições UFC, Fortaleza.

Brummitt, R.F. \& Powell, C.E. 1992. Authors of Plants Names. Royal Botanic Gardens, Kew.

Camargo, R.A. \& Miotto, S.T.S. 2004. O gênero Chamaecrista Moench (Leguminosae-Caesalpinioideae) no Rio Grande do Sul. Iheringia, Série Botânica 59: 131-148.

Cestaro, L.A. 2002. Fragmentos de Florestas Atlânticas no Rio Grande do Norte, Relações estruturais, florísticas e fitogeográfica. Tese de Doutorado, Universidade Federal de São Carlos, São Carlos.

Conceição, A.S. 2000. O gênero Chamaecrista Moench. (Leguminosae - Caesalpinioideae) em Catolés, Abaira, Chapada Diamantina - BA, Brasil. Dissertação de Mestrado, Universidade Federal de Pernambuco, Recife.

Conceição,A.S., Queiroz, L.P. \& Lewis G.P. 2001. Novas espécies de Chamaecrista Moench (LeguminosaeCaesalpinioideae) da Chapada Diamantina, Bahia, Brasil. Sitientibus, Série Ciências Biológicas 1: 112119.

Costa, C.R.A. 1996. Estudo taxonômico de Chamaecrista Moench. (Leguminosae-Caesalpinioideae), ocorrente no litoral de Pernambuco. Dissertação de Mestrado, Universidade Federal de Pernambuco, Recife.

Faria, S.M., Lima, H.C., Ribeiro, R.D., Castilho, A.F., Henriques, J.C. 1989. Ocurrence of nodulation in the Leguminosae. New Phytologist 111: 607-619.

Filardi, F.L.R., Garcia, F.C.P., Carvalho-Okano, R.M., Rodrigues, I.M.C. 2000. Revista Brasileira de Biociências 5: 116-118.

Freire, M.S.B. 1990. Levantamento florístico do Parque Estadual das Dunas do Natal. Acta Botanica Brasilica 4:1990.
Holmgren, P.K., Holmgren, N.H. \& Barnett, L.C. 1990. Index herbariorum. Part 1: The herbaria of the world. 8 ed. New York Botanical Garden, New York.

Irwin, H.S. \& Barneby, R.C. 1982. The American Cassinae. A sinoptical revision of Leguminosae Tribe Cassieae in the New World. Memoirs of the New York Botanical Garden 35: 637-918.

Lewis, G.P. 1987. Legumes of Bahia. Royal Botanic Gardens, Kew.

Lewis, G. P., Schrire, B., Mackinder, B.\& Lock, M. 2005. Legumes of the word. Royal Botanic Gardens, Kew.

Lorenzi, H. 2000. Plantas daninhas do Brasil: terrestres, aquáticas, parasitas e tóxicas. $3^{\mathrm{a}}$ ed. Instituto Plantarum, Nova Odessa.

Nunes, E. 2000. O meio ambiente da grande Natal. Imagem Gráfica, Natal.

Porto, P.A.F., Almeida, A., Pessoa, W.J., Trovão, D. \& Felix, L.P. 2008. Composição florística de um inselberg no agreste paraibano, município de Esperança, Nordeste do Brasil. Revista Caatinga 21: 214-223.

Radford, A.E., Dickson, W.C. \& Massey, J.R. 1974. Vascular plant systematics. Harper \& Row, New York.

SEPLAN. 1985. Diagnóstico preliminar das condições ambientais da grande Natal - RN. Secretaria do Planejamento,Coordenadoria do Meio Ambiente, Natal

Rocha, P.L.B., Queiroz, L.P. \& Pirani, J.R. 2004. Plant species and habitat structure in a sand dune field in the Brazilian Caatinga: a homogeneous habitat harbouring an endemic biota. Revista Brasileira de Botânica 27: $739-755$.

Stearn, W.T. 1992. Botanical Latin. 4 ed. Redwood Press, London.

Tavares, S. 1983. Estudos geobotânicos no Rio Grande do Norte. Coleção Mossoroense. Série B, 323: 39-51. 